DOI: http://doi.org/10.21698/simi.2017.0030

\title{
DETERMINATION OF ESTROGENIC STEROIDS IN SEWAGE SLUDGE SAMPLES FROM EIGHT DOMESTIC WASTEWATER TREATMENT PLANTS
}

Jana Petre, Toma Galaon, Vasile Ion Iancu, Marcela Niculescu

National Research and Development Institute for Industrial Ecology - ECOIND,

71-73 Drumul Podu Dambovitei, sector 6, 060652, Bucharest, Romania, janapetre@gmail.com

\begin{abstract}
Sludges from urban wastewater treatment plants (WWTPs) were tested for the presence of the following natural and synthetic estrogenic steroids: estrone, $17 \alpha-$ estradiol, 17 $\beta$-estradiol, estriol, 17 $\alpha$-ethinylestradiol and equiline. The method involved ultrasonic extraction followed by solid phase extraction cleanup and liquid chromatography tandem mass spectrometry coupled with electrospray ionization in the negative mode. The steroids were identified and determined by internal standard method in selected multiple reaction monitoring mode. All target compounds were detected in the investigated sludge samples. The highest estrogen concentrations were determined for estrone, which reached $164.4 \mathrm{ng} / \mathrm{g}$ in one sample. Synthetic estrogen $17 \alpha$-ethinylestradiol was detected in $50 \%$ of the analyzed samples, in concentrations ranging from 2.7 to $16.1 \mathrm{ng} / \mathrm{g}$.
\end{abstract}

Keywords: determination, estrogenic steroids, liquid chromatography, sludge

\section{Introduction}

Estrogenic steroids are chemicals that have the ability to interfere with the normal function of the endocrine systems of humans and animals. Their pathway to the environment is mainly through wastewater effluents from municipal treatment plants, hospital effluents and from livestock activities. WWTPs wastewater effluents are discharged into the river while the sludges, resulted during biological and chemical processes, that contain a large variety of substances including estrogens are used as fertilizer (Aris et al. 2014). It is important to control the presence of estrogenic steroids in sewage sludge because these contaminants can penetrate into the food chain (Nieto et al. 2008).

The purpose of this study was the determination of six natural and synthetic estrogens estrone (E1), 17 $\alpha$-estradiol $(\alpha \mathrm{E} 2)$, 17 $\beta$-estradiol $(\beta E 2)$, estriol (E3), 17 $\alpha$ ethinylestradiol (EE2) and equiline (Eq) in sewage sludges collected from eight selected wastewater treatment plants (WWTPs) which can be found in some cities in the south-east of Romania. To achieve this goal, a method consisting of ultrasonic extraction and silica gel cleanup followed by LC-MS/MS analysis was optimized.

\section{Experimental part}

Materials and Reagents

Reference standards of estrogens (E1, $\alpha$ E2, $\beta E 2, E E 2, E 3$ and Eq) with purity between $98.4 \%$ and $99.8 \%$ were obtained from Sigma-Aldrich (Steinheim, Germany). Isotopically labelled estrogens, 17 $\beta$-Estradiol-16,16,17-d3 ( $\beta E 2-\mathrm{d} 3$ ) used as surrogate internal standard was obtained from TRC Inc. (Toronto, Ontario, Canada) 


\section{INTERNATIONAL SYMPOSIUM "THE ENVIRONMENT AND THE INDUSTRY", SIMI 2017, PROCEEDINGS BOOK}

and ${ }^{13} \mathrm{C} 2$-Ethinylestradiol $\left({ }^{13} \mathrm{C} 2\right.$-EE2) in acetone $(100 \mu \mathrm{g} / \mathrm{mL})$ used as injection internal standard for the quantitation of the six targeted estrogens was acquired from Cambridge Isotope Laboratories Inc. (Andover, MA, USA). HPLC grade acetonitrile and methanol were acquired from Merck. $\mathrm{HCOOH}$ (p.a.) and $\mathrm{NH}_{4} \mathrm{OH} 25 \%$ (p.a.) were obtained from Sigma-Aldrich. HPLC grade water was obtained in-house using a MilliQ instrument. Oasis HLB $(500 \mathrm{mg} / 6 \mathrm{~mL})$ cartridges were acquired from Waters (Milford, Massachusetts, USA). Stock solution of individual standards were prepared by dissolving each compounds in methanol at a concentration of $1000 \mathrm{mg} / \mathrm{L}$ and stored at $-18^{\circ} \mathrm{C}$ for later use. Working standard solutions were prepared daily by diluting this solution with binary mixture water: methanol (50:50, v/v). All glassware was hand-washed with detergent (Extran) and tap water and rinsed with HPLC grade water.

\section{Sample collection}

The sewage sludge samples were collected from eight domestic wastewater treatment plants in Brăila, Buzău and Calarași Counties. The collected samples were grab samples of sludge and were kept on ice during tranzit to the laboratory where they were stored at $-20^{\circ} \mathrm{C}$ until treatment took place. Sludge samples were first lyophilized in a Christ Alpha 1-2 LD lyophilizer (Martin Christ GmbH, Germany) for 24 hours, crushed and homogenized by a mortar and pestle, sieved (particle size $<100 \mu \mathrm{m}$ ) and stored in glass bottles at $-20^{\circ} \mathrm{C}$ until they were analysed.

\section{Chromatographic analysis}

The chromatographic method was described elsewhere (Galaon et al. 2016). To sum it up, the target compounds were analyzed by HPLC-MS/MS with electrospray ionization. Liquid chromatography was performed on an Agilent 1260 series system (Agilent Technologies) equipped with a degasser, a binary pump, a column oven and an auto sampler. All the analyte were separated on an Zorbax Eclipse Plus C18 (150 x $2.1 \mathrm{~mm}, 3.5 \mu \mathrm{m})$ column Agilent Technologies that was kept at $20^{\circ} \mathrm{C}$. All experiments were performed in gradient elution conditions with a flow rate at 0.25 $\mathrm{mL} / \mathrm{min}$. Mobile phase composition was a mixture of aq. $0.01 \% \mathrm{NH}_{4} \mathrm{OH}$ and $\mathrm{MeOH}$. Mass spectrometry was performed using an Agilent 6410B Triple Quadrupole detector.

\section{Results and Discussions}

\section{Sample extraction and cleanup optimization}

Sludge sample extraction method was developed by optimizing different extraction solvents: methanol, ethyl acetate, acetonitrile, ethyl acetate/methanol, methanol/acetone. All the experiments were performed by spiking $100 \mathrm{ng} / \mathrm{g}$ of each target compounds and surrogate internal standard to $0.5 \mathrm{~g}$ freeze-dried sludge. It was found that binary mixture of methanol/acetone $(5: 2, \mathrm{v} / \mathrm{v})$ as extraction solvent gives better recoveries. The final optimized method for simultaneous extraction and cleanup of 6 steroids in sludge using $0.5 \mathrm{~g}$ sludge and methanol/acetone $(5: 2, \mathrm{v} / \mathrm{v})$ as extraction solvent is given as follows. Sludge samples were extracted successively twice with 5 $\mathrm{mL}$ of methanol and $2 \mathrm{ml}$ acetone in an ultrasonic bath for 15 minutes $\left(30^{\circ} \mathrm{C}\right)$ and then centrifuged at $3000 \mathrm{rpm}$ for $20 \mathrm{~min}$. The supernatants obtained from each extraction step were combined and transfered by a glass pipette into extraction vials and evaporated to dryness under a gentle nitrogen stream $\left(45^{\circ} \mathrm{C}\right)$. The extracts were 


\section{INTERNATIONAL SYMPOSIUM "THE ENVIRONMENT AND THE INDUSTRY", SIMI 2017, PROCEEDINGS BOOK}

re-dissolved in $100 \mathrm{~mL}$ HPLC grade water. In order to reduce the matrix interferences, further cleanup of the obtained extracts is necessary (Liu et al, 2011). For this, the automated SPE system AutoTrace 280 Thermo Scientific Dionex was used. In the purification step, the elution solvent is the most important parameter. The best elution solvent should be able to elute the target compounds, have good recovery, and reduce the interference of other compounds and matrix substances. Taking into account that the polarities of the target compounds are of medium level (log $\mathrm{K}_{\mathrm{ow}}$ : 2.527-4.146), the polar mixture of methanol and water was tested. The cartridges were conditioned with $10 \mathrm{~mL}$ of methanol and $10 \mathrm{~mL}$ of water at a flow rate of $1 \mathrm{~mL} / \mathrm{min}$, adjusted by vacuum pump with an air flow rate of $15 \mathrm{~mL} / \mathrm{min}$. After the entire sample was passed through the cartridge at a flow rate of $10 \mathrm{~mL} / \mathrm{min}$, the adsorbent phase was washed with $10 \mathrm{~mL}$ of ultrapure water at a flow rate of $20 \mathrm{~mL} / \mathrm{min}$. The adsorbent was then dried with a gentle stream of nitrogen for 5 minutes. The analytes were eluted in a concentration tube with $2 \times 2 \mathrm{~mL}$ methanol at a flow rate of $5 \mathrm{~mL} / \mathrm{min}$.

The extracts were concentrated to near dryness with a gentle stream of nitrogen in a water bath $\left(45 \pm 5{ }^{\circ} \mathrm{C}\right)$, after which was added $0.1 \mathrm{~mL}(100 \mathrm{ng} / \mathrm{g})$ of ${ }^{13} \mathrm{C}_{2}$-EE2 injection internal standard, with the purpose of following the effect induced by the sample matrix, and then reconstituted to a volume of one milliliter with a binary methanolwater mixture (50:50, v/v) and transferred to an LC vial for chromatographic analysis. Solutions that showed visible particles in the extract or were turbid were filtered through a $0.45 \mu \mathrm{m}$ Millipore filter before being introduced into the vial.

\section{Method validation}

The method was validated for this type of matrix of sludge sample in terms of recovery, precision, LODs and LOQs. Using the optimized extraction and instrumental methods, good recoveries were achieved for all targeted compounds (Table 1). The intra-day, inter-day method precision and recovery were tested on 3 replicates by spiking $100 \mathrm{ng} / \mathrm{g}$ of estrogens mixture into $0.5 \mathrm{~g}$ of sludge. Recovery was situated between 71 and $104 \%$ with internal standard correction.

\section{Application to real samples}

The optimized method was applied to eight dehydrated sewage sludge samples collected in May 2016 from different municipal WWTPs. Fig. 1 shows the results of this study. In the samples analyzed, Estrone occurred in $90 \%$ of samples in concentrations ranging from 18.3 to $164.4 \mathrm{ng} / \mathrm{g}$ d.w. $17 \beta$-Estradiol was quantified only in one sample at level of $5.9 \mathrm{ng} / \mathrm{g} \mathrm{d}$.w. For as far as Equline is concerned, it was found in three samples at levels below $121.7 \mathrm{ng} / \mathrm{g} \mathrm{d} . \mathrm{w}$. Estriol was detected in $60 \%$ of sludge samples in concentrations that varied from 4.5 to $16.6 \mathrm{ng} / \mathrm{g} \mathrm{d} . \mathrm{w}$, with a mediane of $9.1 \mathrm{ng} / \mathrm{g}$ d.w.

$17 \alpha$-ethynylestradiol, a synthetic hormone which is a derivative of the natural hormone estradiol, was found in 4 samples in concentrations ranging from $2.7 \mathrm{ng} / \mathrm{g}$ to $16.1 \mathrm{ng} / \mathrm{g}$ (d.w.). These results are in agreement with the reported values for some sewage sludges samples collected in France (Díaz-Cruz et al. 2009). It is well known that EE2 has the ability to alter the endocrine systems of exposed organisms, even in low concentrations. Consequently, the occurrence of this compound has become a widespread concern in the topic of environmental protection due to its high resistence to the process of degradation and among others, also due to its tendency to accumulate in organic matter (Aris et al. 2014). 
Table 1. Intra-day and inter-day precision, recoveries and detection and quantification limits of estrogens in sludge samples by HPLC-MS/MS (100 ng/g)

\begin{tabular}{|c|c|c|c|c|c|}
\hline \multirow{2}{*}{ Compound } & \multicolumn{2}{|c|}{ Precision } & \multirow{2}{*}{$\begin{array}{c}\text { Overall } \\
\text { method } \\
\text { recovery }\end{array}$} & \multirow{2}{*}{$\begin{array}{c}\text { LOD } \\
(\mathbf{n g} / \mathbf{g})^{\mathbf{b}}\end{array}$} & \multirow{2}{*}{$\begin{array}{c}\text { LOQ } \\
(\mathrm{ng} / \mathrm{g})^{\mathrm{b}}\end{array}$} \\
\hline & $\begin{array}{c}\text { Intra-day } \\
(\mathrm{ng} / \mathrm{g})^{\mathrm{a}}\end{array}$ & $\begin{array}{c}\text { Inter-day } \\
(\mathrm{ng} / \mathrm{g})^{\mathrm{a}}\end{array}$ & & & \\
\hline E3 & $11.7 \pm 0.8$ & $10.6 \pm 1.7$ & $84.5 \pm 10$ & 1.18 & 3.95 \\
\hline $\mathrm{Eq}$ & $122.9 \pm 6.7$ & $120.9 \pm 14.5$ & $84.1 \pm 8$ & 0.07 & 0.24 \\
\hline E1 & $49.6 \pm 1.4$ & $50.5 \pm 4.6$ & $86.6 \pm 13$ & 0.39 & 1.31 \\
\hline$\beta E 2$ & $5,3 \pm 0,5$ & $5.7 \pm 0.8$ & $71.3 \pm 7$ & 0.73 & 2.43 \\
\hline EE2 & $3.9 \pm 0.2$ & $4.2 \pm 1.0$ & $91.0 \pm 8$ & 0.54 & 1.79 \\
\hline$\alpha \mathrm{E} 2$ & $5.5 \pm 0.6$ & $6.5 \pm 1.2$ & $104.1 \pm 14$ & 1.05 & 3.49 \\
\hline
\end{tabular}

${ }^{\mathrm{a}}$ Mean $(\%) \pm$ standard deviation $(\%)(\mathrm{n}=3$, replicate samples at the same time)

${ }^{b} \mathrm{LOD}$, method limit of detection; LOQ, method limit of quantification

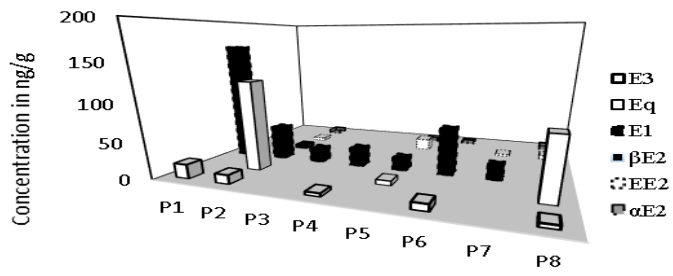

WWTP

Figure 1. Results in ng/g (d.w.) of sewage sludge samples analyzed

As an example, Fig. 2 shows the MRM chromatograms of the P1 sample where the presence of Estriol (19.6 ng/g d.w.) and Estrone (164.4 ng/g d.w.) can be seen.

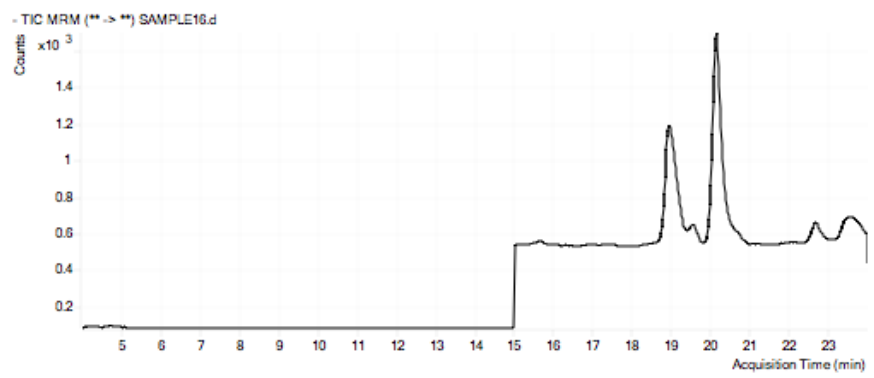


Figure 2. MRM chromatogram obtained by HPLC-MS/MS of sewage sludge collected from WWTP1

\section{Conclusions}

A sensitive method was applied to the analysis of eight sludge samples from different municipal WWTPs. The concentrations of detected residual estrogenic steroids in sludge samples varied greatly from $2.7 \mathrm{ng} / \mathrm{g} \mathrm{d}$.w. to $164.4 \mathrm{ng} / \mathrm{g} \mathrm{d}$.w. The most frequently detected compounds were Estrone and Estriol, with the latter having the highest concentrations.

\section{Acknowledgements,}

This work has been supported by the Romanian Government through the project PN 162501 06 , contract no. $38 \mathrm{~N} / 2016$.

\section{References}

Aris, AZ, Shamsuddin, AS \& Praveena, SM 2014, 'Occurrence of $17 \alpha$-ethynul estradiol (EE2) in the environment and effect on exposed biota: a review', Environment International, vol. 69, pp. 104-119.

Díaz-Cruz, M S, García-Galán, MJ, Guerra, P, Jelic, A, Postigo, C, Eljarrat, E, Farré, M, López de Alda, MJ, Petrovic, M, Barceló, D 2009, 'Analysis of selected emerging contaminants in sewage sludge', Trends in Analytical Chemistry, vol. 28, no. 11, pp. 1263-1275.

Galaon, T, Petre, J, Iancu, V I, Cruceru, L, Vasile, GG, Pascu, LF, Lehr, CB 2016, 'Detection of Estrogen Hormones in Danube River and Tributaries Using Liquid Chromatography-Mass Spectrometry', Revista de chimie (Bucharest), vol. 67, no. 8, pp. 1474-1478.

Liu, S, Ying, G-G, Zhao, J-L, Chen, F, Yang, B, Zhou, L-J \& Lai, H-J 2011, 'Trace analysis of 28 steroids in surface water, wastewater and sludge samples by rapid resolution liquid chromatography-electrospray ionization tandem mass spectrometry', Journal of Chromatography A, vol. 1218, no. 10, pp. 1367-1378.

Nieto, A, Borrull, F \& Marcé, R M 2008, 'Determination of natural and synthetic estrogens and their conjugates in sewage sludge by pressurized liquid extraction and liquid chromatography-tandem mass spectrometry', Journal of Chromatography A, vol. 1213, no. 2, pp. 224-230. 